\title{
PENERAPAN METODE GOAL PROGRAMMING UNTUK MENGOPTIMALKAN PERSEDIAAN BBM DI KOTA POSO BERBASIS PENINGKATAN KENDARAAN STUDI KASUS : PT. PERTAMINA UPMS VII TERMINAL BBM POSO
}

\author{
M. Fauji1 ${ }^{1}$ A. Sahari² dan R. Ratianingsih ${ }^{3}$ \\ 1,2,3 Program Studi Matematika Jurusan Matematika FMIPA Universitas Tadulako \\ Jalan Soekarno-Hatta Km. 09 Tondo, Palu 94118, Indonesia. \\ 1fauji37@yahoo.co.id, 2agus_sh@yahoo.com,3ratianingsih@yahoo.com
}

\begin{abstract}
Pertamina is a company that is responsible for the adequacy of the supply of fuel (BBM) according to the needs of society. PT. Pertamina UPms VII Fuel Terminal Poso Group is one of the branches of PT. Pertamina, which is responsible for fuel distribution in Poso, Central Sulawesi. During this time the fuel supply in the city of Poso only based on quotas determined in conformity with the state budget only. Whereas the growth of motor vehicle becomes the most important thing that should be considered in determining the fuel supply, therefore, this study aims to design an optimal fuel supply adjusted for the increase in the number of vehicles and the amount of benefits to be achieved. The type of supplied fuel are a premium, pertamax and diesel, while the used method is the Goal Programming. This method is a modification or special variation of the linear program that can solve the problems that have more than one purpose. For reference data in February 2014; with the mothly increasing of private motor bike of 52 units, private cars of 10 units, commercial transportation by 1 unit, the results showed that the monthly optimal supply of fuel of March - December 2014should be increased periodically with the increase rate is $2.543,60$ liters for premium and $1.363,63$ liters for diesel. Optimal inventory in relatif the months refers to the optimal inventory an February amounted premium 1.156 .000 liters, amounted diesel 352.000 liters and 482.000 liters of pertamax. The firm increases its profit Rp. 494.400.000, as muchs it means that the increasing of net profit is $\mathrm{Rp}$.
\end{abstract} 165.200.000.

Keywords $\quad$ : Fuel, Goal Programming, Optimal Inventory, Vehicle Number

\begin{abstract}
ABSTRAK
Pertamina merupakan suatu perusahaan yang bertanggung jawab terhadap kecukupan persedian bahan bakar minyak (BBM) sesuai kebutuhan masyarakat. PT. Pertamina UPms VII Terminal BBM Poso Group merupakan salah satu cabang PT. Pertamina yang bertanggungjawab terhadap penyaluran BBM di Kota Poso, Sulawesi Tengah. Selama ini persediaan BBM di Kota Poso hanya berdasarkan atas kuota yang ditentukan sesuia dengan APBN saja. Padahal pertumbuhan kendaraan bermotor menjadi hal paling penting yang semestinya dipertimbangkan dalam penentu persediaan BBM, Oleh karena itu, penelitian ini bertujuan untuk merancang persedian optimal BBM yang disesuaikan dengan peningkatan banyaknya jumlah kendaraan dan besarnya
\end{abstract}


keuntungan yang ingin dicapai. Jenis BBM yang disalurkan adalah premium, pertamax dan solar, sedangkan metode yang digunakan adalah Goal Programming. Metode ini merupakan modifikasi atau variasi khusus program linier yang dapat menyelesaikan permasalahan yang memiliki lebih dari satu tujuan. Untuk data acuan Maret 2014 , dengan peningkatan perbulan kendaraan sepeda motor pribadi sebesar 52 unit, mobil pribadi sebesar 10 unit, angkutan niaga sebesar 1 unit, hasil penelitian menunjukan bahwa persediaan optimal BBM untuk bulan Maret Desember 2014 harus meningkat secara periodik dengan tingkat pertambahan sebesar 2.543,60 liter perbulan untuk premium dan solar sebesar 1.363,63 liter perbulan. Persediaan optimal pada bulan-bulan tersebut mengacu pada persediaan optimal premium pada bulan Februari sebesar 1.156.000 liter, solar sebesar 352.000 liter dan pertamax sebesar 482.000 liter. Keuntungan perusahaaan dapat mencapai sebesar Rp. 494.400.000, dengan peningkatan keuntungan sebesar Rp. 165.200.000.

Kata Kunci $\quad$ : BBM, Goal Programming, Jumlah Kendaraan, Persedian Optimal

\section{PENDAHULUAN}

\subsection{Latar Belakang}

Indonesia merupakan negara yang menduduki peringat pertama dalam jumlah kendaraan terbanyak di Asia Tenggara (Tempo.co, 2011). Jumlah kendaraan di Indonesia setiap tahunnya mengalami peningkatan, pada tahun 2013 jumlah kendaraan di Indonesia mencapai 104 juta (BPS). Dengan peningkat jumlah kendaraan di setiap tahun maka kebutuhan Bahan Bakar Minyak (BBM) akan meningkat pula disetiap tahunnya. Permintaan BBM yang terus meningkat tersebut menyebabkan perusahaan seperti Pertamina memerlukan prediksi persediaan BBM optimal yang tepat.

Mengingat Pertamina merupakan suatu perusahaan yang harus menjaga persediaan bahan bakar yang cukup untuk kebutuhan masyarakat, maka prediksi persedian BBM optimal sangat penting bagi Pertamina dalam mengoptimalkan, Pertamina juga harus mempertimbangkan banyaknya kebutuhan BBM yang disalurkan agar sesuai dengan kebutuhan masyarakat dengan tetap memperhatikan kuota yang telah ditetapkan. Ketepatan prediksi BBM optimal secara tidak langsung membantu pemerintah dalam hal menghemat penyaluran BBM bersubsidi sehingga meminimalisir beban biayai BBM bersubsidi.

BBM subsdi merupakan bahan bakar minyak yang jual kkepada masyarakat dengan harga dibawah harga bahan bakar dunia. Hal ini dikarenakan rakya telah mendapat bantuan dana dalam bentuk potongan harga sebelum sampai kie tangan konsumen. Selain BBm bersubsidi, terdapat juga BBM nonsubsidi yang tidak mendapatkan subsidi dari pemerintah. Konsekunsi harga BBm nonsubsidi lebih mahal dibandingkan dengan BBM subsidi (Fiskal.2014). Kita perlu memperhatikan sasaran BBM subsidi yang diperuntukan bagi 
kelompok tertentu. Pemerintah telah mengatur penggunan BBM subsidi melalui Permen ESDM NO. 1 Tahun 202, bahwa "kendaraan dinas tidak diperbolehkan menggunakan BBM subsidi". Pemerintah menentukan kuota BBM bersubsidi berdasarkan Rancangan undang-undang APBN (Metrotvnews.com, 2014). Sehingga persediaan BBM subsidi dirancang hanya berdasarkan APBN bukan berdasarkan kebutuhan konsumen (jumlah kendaraan).

Dalam penelitan ini, dilakukan studi kasus pada PT. Pertamina Unit Pemasaran VII Terminal BBM Poso. Pengoptimalan persedian BBM subsidi dan nonsubsidi yang tidak melebihi kuota dan sesuai dengan jumlah kendaraan yang ada di Kota Poso menjadi fokus penelitian ini. Pengoptimalan yang dilakukan ditentukan pula berdasarkan pengkategorian jenis kendaraan.

\subsection{Rumusan Masalah}

Berdasarkan uraian di atas, maka permasalahan pada penelitian ini adalah berapa banyaknya persedian optimal BBM Subsidi dan Non Subsidi per bulan sesuai peningkatan kendaraan serta besarnya keuntungan yang ingin dicapai PT. Pertamina Unit Pemasaran VII Terminal BBM Poso dengan menggunakan metode Goal Programming.

\subsection{Tujuan}

Tujuan dari penelitian ini adalah mendapatkan banyaknya persedian optimal BBM Subsidi dan Non Subsidi sesuai peningkatan kendaraan serta besarnya keuntungan yang ingin dicapai PT. Pertamina Unit Pemasaran VII Terminal BBM Poso dengan menggunakan metode Goal Programming.

\subsection{Manfaat Penelitian}

Adapun manfaat dari penelitian ini, yaitu:

1. Sebagai masukan dan sumbangan pemikiran untuk dijadikan dasar kebijakan Pertamina dalam penyedian BBM agar sesuai dengan jumlah kendaraan yang menggunakannya.

2. Sebagai pengembangan dari matakuliah Program Linear sehingga dapat digunakan untuk memanmbah pengetahuan para pembaca.

3. Sebagai acuan dari penelitian lain untuk lebih mengembangkan literatur dan materi yang digunakan.

\subsection{Batas Masalah}

1. Persedian BBM yang di teliti hanya sebatas wilayah Kota Poso

2. BBM yang diteliti adalah BBM subsidi (premium dan solar) dan BBM nonsubsidi (pertamax). 


\subsection{Asumsi Penelitian}

Pengisian BBM maksimal pada sepeda motor sebesar Rp. 20.000/hari, mobil pribadi Rp.100.000/hari, angkutan umum (mikrolet) Rp. 150.000/hari dan angkutan niaga (truk, bus) Rp. 250.000/hari/ keuntungan penjualan BBM Rp.200/liter.

\section{METODE PENELITIAN}

Langkah-langkah yang dilakukan dalam penelitian ini yaitu

a. Memulai penelitian.

b. Pengambilan data.

c. Membangun model matematika.

d. Menyelesaikan model matematika menggunakan metode Goal Programming pada aplikasi QM for Windows.

e. Interpretasi Solusi model.

f. Menyimpulkan hasil penelitian.

g. Selesai.

\section{HASIL DAN PEMBAHASAN}

\subsection{Pengumpulan Data}

Data yang diperlukan dalam penelitian ini adalah banyak jumlah kendaraan dinas, kendaraan pribadi, Kendaraan umum dan penyaluran BBM.

Tabel 1 : Kendaraan Dinas pada Tahun 2014

\begin{tabular}{|l|l|c|}
\hline No & \multicolumn{1}{|c|}{ Jenis Kendaraan } & Jumlah \\
\hline 1 & Sepeda Motor & 1.439 \\
\hline 2 & Mobil & 466 \\
\hline 3 & Kendaraan niaga & 32 \\
\hline
\end{tabular}

Sumber : Pemda Kabupaten Poso

Tabel 2 : Kendaraan Pribadi dan Umum

\begin{tabular}{|c|c|c|c|c|c|}
\hline \multirow[b]{2}{*}{ No } & \multirow[b]{2}{*}{ Bulan } & \multicolumn{4}{|c|}{ Jenis Kendaraan } \\
\hline & & $\begin{array}{c}\text { Sepeda Motor } \\
\text { Pribadi }\end{array}$ & Mobil Pribadi & $\begin{array}{c}\text { Angkutan } \\
\text { Umum }\end{array}$ & $\begin{array}{c}\text { Angkutan } \\
\text { Niaga }\end{array}$ \\
\hline 1 & Februari & 1.971 & 212 & 1120 & 501 \\
\hline 2 & Maret & 1.964 & 249 & 1106 & 497 \\
\hline 3 & April & 2.106 & 257 & 1096 & 502 \\
\hline 4 & Mei & 2.261 & 257 & 1086 & 506 \\
\hline 5 & Juni & 2.438 & 263 & 1063 & 510 \\
\hline 6 & Juli & 2.160 & 289 & 1069 & 504 \\
\hline
\end{tabular}




\begin{tabular}{|l|l|l|l|l|l|}
\hline 7 & Agustus & 2.668 & 295 & 1083 & 499 \\
\hline 8 & September & 2.337 & 283 & 1052 & 505 \\
\hline
\end{tabular}

Sumber : Samsat Kab. Poso dan Dishubkominfo Kab. Poso

Tabel 3 : Penyaluran BBM pada Tahun $2014\left(a_{i, j}\right)$

\begin{tabular}{|c|l|c|c|c|}
\hline \multirow{2}{*}{ No } & \multirow{2}{*}{ Bulan } & \multicolumn{3}{c|}{ Jenis BBM } \\
\cline { 3 - 5 } & & Premium & Solar & Pertamax \\
\hline 1 & Agustus & 1.215 & 550 & - \\
\hline 2 & Februari & 1.156 & 482 & - \\
\hline 3 & Maret & 1.285 & 521 & - \\
\hline 4 & April & 1.301 & 517 & - \\
\hline 5 & Mei & 1.266 & 602 & - \\
\hline 6 & Juni & 1.226 & 611 & 8 \\
\hline 7 & Juli & 1.327 & 653 & 8 \\
\hline 8 & Agustus & 1.357 & 608 & - \\
\hline 9 & September & 1.360 & 632 & \\
\hline
\end{tabular}

Tabel 4 : Batas Pengisian untuk Masing-masing Kendaraan

\begin{tabular}{|c|l|c|c|c|c|}
\hline \multirow{2}{*}{ No } & \multirow{2}{*}{ Jenis Kendaraan } & \multicolumn{2}{|c|}{$\begin{array}{r}\text { Batas pengisian BBM } \\
\text { per Hari }\end{array}$} & \multicolumn{2}{c|}{$\begin{array}{r}\text { Batas pengisian BBM per } \\
\text { Bulan }\end{array}$} \\
\cline { 3 - 6 } & & Rupiah & Liter & Rupiah & Liter \\
\hline 1 & sepeda motor & 20.000 & 3,07 & 600.000 & 92,3 \\
\hline 2 & Mobil & 100.000 & 15,4 & 3.000 .000 & 461,5 \\
\hline 3 & $\begin{array}{l}\text { Angkutan umum } \\
\text { (mikrolet) }\end{array}$ & 150.000 & 23,1 & 4.500 .000 & 692,3 \\
\hline 4 & $\begin{array}{l}\text { Angkutan Niaga (Truk } \\
\text { dan bus) }\end{array}$ & 250.000 & 45,5 & 7.500 .000 & $1.363,6$ \\
\hline
\end{tabular}

Tabel 5 : Kebutuhan Premium Bulan Februari $\left(b_{2}\right)$

\begin{tabular}{|c|l|r|r|r|}
\hline No & \multicolumn{1}{|c|}{ Jenis Kendaraan } & \multicolumn{1}{c|}{$\begin{array}{c}\text { Jumlah } \\
\text { kendaraan (Unit) }\end{array}$} & $\begin{array}{c}\text { Batas pengisian BBM } \\
\text { per bulan (liter) }\end{array}$ & $\begin{array}{r}\text { Total } \\
\text { (liter) }\end{array}$ \\
\hline 1 & Sepeda motor & 1.971 & 93,3 & $183.894,30$ \\
\hline 2 & Mobil & 212 & 461,5 & $97.838,00$ \\
\hline 3 & Angkutan umum (Mikrolet) & 1.120 & 692,3 & $775.376,00$ \\
\hline \multicolumn{2}{|l|}{ Jumlah } & 3.303 & & $1.057 .108,30$ \\
\hline
\end{tabular}


Tabel 6 : Kebutuhan Pertamax Bulan Mei ( $\left.b_{1}\right)$

\begin{tabular}{|l|l|c|c|c|}
\hline No & Jenis Kendaraan & $\begin{array}{c}\text { Jumlah } \\
\text { kendaraan (Unit) }\end{array}$ & $\begin{array}{c}\text { Batas pengisian BBM per } \\
\text { bulan (liter) }\end{array}$ & $\begin{array}{c}\text { Total } \\
\text { (liter) }\end{array}$ \\
\hline 1 & Sepeda Motor & 1.439 & 93,3 & $134.258,70$ \\
\hline 2 & Mobil & 466 & 461,5 & $215.059,00$ \\
\hline \multicolumn{2}{|l}{ Jumlah } & 1.905 & & $349.317,70$ \\
\hline
\end{tabular}

Tabel 7 : Kebutuhan solar bulan Februari $\left(b_{3}\right)$

\begin{tabular}{|l|l|r|r|r|}
\hline No & \multicolumn{1}{|c|}{ Jenis Kendaraan } & $\begin{array}{c}\text { Jumlah kendaraan } \\
\text { (Unit) }\end{array}$ & $\begin{array}{c}\text { Batas pengisian BBM per } \\
\text { bulan (liter) }\end{array}$ & $\begin{array}{c}\text { Total } \\
\text { (liter) }\end{array}$ \\
\hline 1 & $\begin{array}{l}\text { Angkutan niaga } \\
\text { (umum) }\end{array}$ & 501 & $1.363,6$ & $683.163,60$ \\
\hline 2 & $\begin{array}{l}\text { Angkutan niaga } \\
\text { (dinas) }\end{array}$ & 32 & $1.363,6$ & $43.635,20$ \\
\hline \multicolumn{2}{|l|}{ Jumlah } & 533 & & $726.798,80$ \\
\hline
\end{tabular}

\subsection{Penentuan Variabel (Peubah) Keputusan}

$X_{1}=$ Banyaknya penyaluran premium per bulan

$\mathrm{X}_{2}=$ Banyaknya penyaluran pertamax per bulan

$\mathrm{X}_{3}=$ Banyaknya penyaluran solar per bulan

$\mathrm{X}_{4}=$ Penyaluran premium per bulah terhadap kebutuhan konsumen

$\mathrm{X}_{5}=$ Penyaluran pretamax per bulah terhadap kebutuhan konsumen

$\mathrm{X}_{6}=$ Penyaluran solar per bulah terhadap kebutuhan konsumen

\subsection{Membangun Model Matematika}

Fungsi Tujuan

$Z_{\min }=P_{1}\left(d_{1}^{+}+d_{1}^{-}\right)+P_{2}\left(d_{2}^{+}+d_{2}^{-}\right)+P_{3}\left(d_{3}^{+}+d_{3}^{-}\right)+P_{4}\left(d_{4}^{+}+d_{4}^{-}\right)$

Kendala tujuan:

$$
\begin{aligned}
& \text { 1.156.000 } X_{1}+d_{1}^{+}-d_{1}^{-}=1.057 .108,30 \\
& 8.000 x_{2}+d_{2}^{+}-d_{2}^{-}=349.317,70 \\
& 482.000 x_{3}+d_{3}^{+}-d_{3}^{-}=726.798,80 \\
& 200 X_{4}+200 X_{5}+200 X_{6}+d_{4}^{+}-d_{4}^{-}=\text {Rp. } 329.200 .000
\end{aligned}
$$

\subsection{Penyelesaian Model Matematika Menggunakan Metode Goal Programming pada Aplikasi QM For Windows}

Salah satu program aplikasi yang digunakan untuk menyelesaikan masalah program linier yang menggunakan metode Goal Programming yaitu apllikasi QM For Windows. Nilai $X_{i}$ yang diperoleh dari program aplikasi tersebut berturut-berturut $X_{1}=0,91, X_{2}=43,66$ dan $X_{3}=$ 
1,51. Selanjutnya masing-masing nilai $X_{i}$ diubah ke dalam bentuk bilangan integer yaitu $X_{1}=1$, $\mathrm{X}_{2}=44$ dan $\mathrm{X}_{3}=2$.

Kemudian nilai-nilai tersebut dimasukan kedalam fungsi kendala maka diperoleh persedian BBM adalah sebagai berikut, persedian Optimal premium pada bulan Februari sebesar 1.156 .000 liter dengan nilai $\mathrm{d}_{1}^{+}=98.891,70 \square \square \square \square \square$, persedian optimal pertamax pada bulan Mei sebesar 352.000 liter dengan nilai $\mathrm{d}_{2}^{+}=2.682,30 \square \square \square \square \square$. dan persedian optimal solar pada bulan Februari sebesar 964.000 liter dengan nilai $d_{3}^{+}=237.201,20$ liter serta besar keuntungan yang dipeoleh oleh perusahaan sebesar Rp. 494.400 .000 dengan nilai $\mathrm{d}_{4}^{+}=\operatorname{Rp} .165 .200 .000$.

\subsection{Tingkat Pertumbuhan Kendaraan}

Pertumbuhan kendaraan merupakan salah faktor yang mempengaruhi persedian BBM untuk bulan-bulan selanjutnya. Berdasarkan data kendaraan yang ada di Kota Poso, maka dapat ketehaui tingkat pertumbuhan kendaraan di Kota Poso sebagai berikut:

Tabel 8 : Tingkat Pertumbuhan Kendaraan di Kota Poso

\begin{tabular}{|c|l|c|}
\hline No & Jenis kendaraan & Rata-rata pertumbuhan kendaraan perbulan (unit) \\
\hline 1 & Sepeda motor pribadi & 52 \\
\hline 2 & Mobil pribadi & 10 \\
\hline 3 & Angkutan umum & -10 \\
\hline 4 & Angkutan niaga & 1 \\
\hline
\end{tabular}

Dalam penelitian ini peningkatan banyak kendaraan pribadi memberikan dampak terhadap penurunan banyaknya angkutan umum yakni 10 unit dalam perbulan. Dengan meningkatnya jumlah kendaraan di Kota Poso maka jumlah kebutuhan BBM pun meningkat. Peningkatan BBM Kota Poso untuk bulan-bulan selanjutnya diprediksi berdasarkan pertumbuhan kendaraan yang ada di Kota Poso terdapat sebagai berikut:

Tabel 9 : Peningkatan Kebutuhan BBM Perbulan

\begin{tabular}{|c|c|c|c|c|c|c|}
\hline \multirow[t]{2}{*}{ No } & \multirow{2}{*}{$\begin{array}{c}\text { Jenis } \\
\text { Kendaraan }\end{array}$} & \multirow{2}{*}{$\begin{array}{c}\text { Jumlah } \\
\text { pertumbuhan } \\
\text { kendaraan (unit) }\end{array}$} & \multicolumn{2}{|c|}{$\begin{array}{c}\text { Batas pengisian BBM } \\
\text { perbulan (liter) }\end{array}$} & \multicolumn{2}{|c|}{ Jumlah } \\
\hline & & & Premium & Solar & Premium & Solar \\
\hline 1 & $\begin{array}{l}\text { Sepeda Motor } \\
\text { Pribadi }\end{array}$ & 52 & 93,5 & - & $4.851,6$ & - \\
\hline 2 & Mobil Pribadi & 10 & 461,5 & - & $4.615,0$ & - \\
\hline 3 & Angkutan Umum & -10 & 692,3 & - & $-6.923,0$ & - \\
\hline 4 & Angkutan Niaga & 1 & - & $1.363,6$ & - & $1.363,6$ \\
\hline \multicolumn{5}{|c|}{ Total } & $2.543,6$ & $1.363,6$ \\
\hline
\end{tabular}


Berdasarkan data peningkatan kebutuhan BBM perbulan, maka kita bisa memprediksikan kebutuhan BBM dan menentukan persedian optimal untuk bulan selanjutnya. Adapun untuk prediksi kebutuhan BBM pada tabel 4.18 dan persedian optimal pada tabel 4.19 diketahui sebagai berikut :

Tabel 10 : Prediksi Kebutuhan BBM Perbulan berdasarkan Peningkatan Kebutuhan BBM Perbulan

\begin{tabular}{|r|c|c|c|c|}
\hline \multirow{2}{*}{ No } & \multirow{2}{*}{ Bulan } & \multicolumn{3}{|c|}{ Prediksi kebutuhan BBM perbulan (liter) } \\
\cline { 3 - 5 } & & Premium & Pertamax & \multicolumn{1}{l|}{ Solar } \\
\hline 1 & Februari & $1.057 .108,30$ & $349.317,70$ & $726.798,80$ \\
\hline 2 & Maret & $1.059 .651,90$ & $349.317,70$ & $728.162,40$ \\
\hline 3 & April & $1.062 .195,50$ & $349.317,70$ & $729.526,00$ \\
\hline 4 & Mei & $1.064 .739,10$ & $349.317,70$ & $730.889,60$ \\
\hline 5 & Juni & $1.067 .282,70$ & $349.317,70$ & $732.253,20$ \\
\hline 6 & Juli & $1.069 .826,30$ & $349.317,70$ & $733.616,80$ \\
\hline 7 & Agustus & $1.072 .369,90$ & $349.317,70$ & $734.980,40$ \\
\hline 8 & September & $1.074 .913,50$ & $349.317,70$ & $736.344,00$ \\
\hline 9 & Oktober & $1.077 .457,10$ & $349.317,70$ & $737.707,60$ \\
\hline 10 & November & $1.080 .000,70$ & $349.317,70$ & $739.071,20$ \\
\hline 11 & Desember & $1.082 .544,30$ & $349.317,70$ & $740.434,80$ \\
\hline
\end{tabular}

Tabel 11 : Prediksi Persedian Optimal Perbulan berdasarkan Peningkatan Kebutuhan BBM Perbulan

\begin{tabular}{|r|l|c|c|c|}
\hline \multirow{2}{*}{ No } & \multirow{2}{*}{ Bulan } & \multicolumn{3}{|c|}{ Prediksi persedian optimal BBM perbulan (liter) } \\
\cline { 3 - 5 } & & Premium & \multicolumn{1}{c|}{ Pertamax } & \multicolumn{1}{c|}{ Solar } \\
\hline 1 & Februari & $1.156 .000,00$ & $352.000,00$ & $964.000,00$ \\
\hline 2 & Maret & $1.158 .543,60$ & $349.317,70$ & $965.363,60$ \\
\hline 3 & April & $1.161 .087,20$ & $349.317,70$ & $966.727,20$ \\
\hline 4 & Mei & $1.163 .630,80$ & $349.317,70$ & $968.090,80$ \\
\hline 5 & Juni & $1.166 .174,40$ & $349.317,70$ & $969.454,40$ \\
\hline 6 & Juli & $1.168 .718,00$ & $349.317,70$ & $970.818,00$ \\
\hline 7 & Agustus & $1.171 .261,60$ & $349.317,70$ & $972.181,60$ \\
\hline 8 & September & $1.173 .805,20$ & $349.317,70$ & $973.545,20$ \\
\hline 9 & Oktober & $1.176 .348,80$ & $349.317,70$ & $974.908,80$ \\
\hline 10 & November & $1.178 .892,40$ & $349.317,70$ & $976.272,40$ \\
\hline 11 & Desember & $1.181 .436,00$ & $349.317,70$ & $977.636,00$ \\
\hline
\end{tabular}


Tabel 12 : Perbandingan Peningkatan Kebutuhan dengan Penyaluran BBM Perbulan pada Tahun 2014

\begin{tabular}{|c|c|c|c|c|c|c|c|c|c|c|c|}
\hline \multirow{2}{*}{ No } & \multirow{2}{*}{ Bulan } & \multicolumn{3}{|c|}{ Jumlah Kebutuhan BBM perbulan (liter) } & \multicolumn{3}{|c|}{ Penyaluran BBM Perbulan (liter) } & \multicolumn{3}{|c|}{ Nilai $\mathrm{d}_{\mathrm{i}}^{+}$dan $\mathrm{d}_{\mathrm{i}}^{-}$} & \multirow{2}{*}{$\begin{array}{c}\text { Keuntungan } \\
\text { Perusahaan (Rp) }\end{array}$} \\
\hline & & Premium & Pertamax & Solar & Premium & Pertamax & Solar & Premium & Pertamax & Solar & \\
\hline 1 & Februari & $1.057 .108,30$ & $349.317,70$ & $726.798,80$ & 1.156 .000 & 0 & 482.000 & $98.891,70$ & $-349.317,70$ & $-244.798,80$ & 327.600 .000 \\
\hline 2 & Maret & $1.059 .651,90$ & $349.317,70$ & $728.162,43$ & 1.285 .000 & 0 & 521.000 & $225.348,10$ & $-349.317,70$ & $-207.162,43$ & 361.200 .000 \\
\hline 3 & April & $1.062 .195,50$ & $349.317,70$ & $729.526,06$ & 1.301 .000 & 0 & 517.000 & $238.804,50$ & $-349.317,70$ & $-212.526,06$ & 363.600 .000 \\
\hline 4 & Mei & $1.064 .739,10$ & $349.317,70$ & $730.889,69$ & 1.266 .000 & 8.000 & 602.000 & $201.260,90$ & $-341.317,70$ & $-128.889,69$ & 375.200 .000 \\
\hline 5 & Juni & $1.067 .282,70$ & $349.317,70$ & $732.253,32$ & 1.226 .000 & 0 & 611.000 & $158.717,30$ & $-349.317,70$ & $-121.253,32$ & 367.400 .000 \\
\hline 6 & Juli & $1.069 .826,30$ & $349.317,70$ & $733.616,95$ & 1.327 .000 & 8.000 & 653.000 & $257.173,70$ & $-341.317,70$ & $-80.616,95$ & 397.600 .000 \\
\hline 7 & Agustus & $1.072 .369,90$ & $349.317,70$ & $734.980,58$ & 1.357 .000 & 8.000 & 608.000 & $284.630,10$ & $-341.317,70$ & $-126.980,58$ & 394.600 .000 \\
\hline 8 & September & $1.074 .913,50$ & $349.317,70$ & $736.344,21$ & 1.360 .000 & 0 & 632.000 & $285.086,50$ & $-349.317,70$ & $-104.344,21$ & 398.400 .000 \\
\hline & Total & $8.528 .087,20$ & $2.794 .541,60$ & $5.852 .572,04$ & 10.278 .000 & 24.000 & 4.626 .000 & $1.749 .912,80$ & $-2.770 .541,60$ & $-1.226 .572,04$ & 985.600 .000 \\
\hline
\end{tabular}

Tabel 13 : Perbandingan Prediksi kebutuhan BBM dengan Persedian Optimal BBM Perbulan

\begin{tabular}{|c|c|c|c|c|c|c|c|c|c|c|c|}
\hline \multirow{2}{*}{ No } & \multirow{2}{*}{ Bulan } & \multicolumn{3}{|c|}{ Jumlah Kebutuhan BBM perbulan (liter) } & \multicolumn{3}{|c|}{ Penyaluran BBM Perbulan (liter) } & \multicolumn{3}{|c|}{ Nilai $\mathrm{d}_{\mathrm{i}}^{+}$} & \multirow{2}{*}{$\begin{array}{c}\text { Keuntungan } \\
\text { Perusahaan (Rp) }\end{array}$} \\
\hline & & Premium & Pertamax & Solar & Premium & Pertamax & Solar & Premium & Pertamax & Solar & \\
\hline 1 & Februari & $1.057 .108,30$ & $349.317,70$ & $726.798,80$ & 1.156 .000 & 352.000 & 964.000 & $98.891,70$ & $2.682,30$ & $237.201,20$ & 494.400 .000 \\
\hline 2 & Maret & $1.059 .651,90$ & $349.317,70$ & $728.162,43$ & 1.158 .544 & 352.000 & 965.364 & $98.891,70$ & $2.682,30$ & $237.201,20$ & 495.181 .446 \\
\hline 3 & April & $1.062 .195,50$ & $349.317,70$ & $729.526,06$ & 1.161 .087 & 352.000 & 966.727 & $98.891,70$ & $2.682,30$ & $237.201,20$ & 495.962 .892 \\
\hline 4 & Mei & $1.064 .739,10$ & $349.317,70$ & $730.889,69$ & 1.163 .631 & 352.000 & 968.091 & $98.891,70$ & $2.682,30$ & $237.201,20$ & 496.744 .338 \\
\hline 5 & Juni & $1.067 .282,70$ & $349.317,70$ & $732.253,32$ & 1.166 .174 & 352.000 & 969.455 & $98.891,70$ & $2.682,30$ & $237.201,20$ & 497.525 .784 \\
\hline 6 & Juli & $1.069 .826,30$ & $349.317,70$ & $733.616,95$ & 1.168 .718 & 352.000 & 970.818 & $98.891,70$ & $2.682,30$ & $237.201,20$ & 498.307 .230 \\
\hline 7 & Agustus & $1.072 .369,90$ & $349.317,70$ & $734.980,58$ & 1.171 .262 & 352.000 & 972.182 & $98.891,70$ & $2.682,30$ & $237.201,20$ & 499.088 .676 \\
\hline 8 & September & $1.074 .913,50$ & $349.317,70$ & $736.344,21$ & 1.173 .805 & 352.000 & 973.545 & $98.891,70$ & $2.682,30$ & $237.201,20$ & 499.870 .122 \\
\hline & Total & $8.528 .087,20$ & $2.794 .541,60$ & $5.852 .572,04$ & 9.319 .221 & 2.816 .000 & 7.750 .182 & $791.133,60$ & $21.458,40$ & $1.897 .609,60$ & 3.977.080.488 \\
\hline
\end{tabular}


Tabel 10 menunjukan bahwa kebutuhan BBM mengalami peningkatan. Bila prediksi kebutuhan BBM pada bulan Februari 2014 sampai dengan bulan September 2014 dibandingkan dengan penyaluran BBM pada Tabel 3 maka akan diketahui persediaan BBM PT. Pertamina UPms VII Terminal BBM Poso perbulan sudah optimal atau belum optimal (lihat Tabel 12). Tabel 12 memperlihatkan bahwa penyaluran premium mengalami kelebihan dari jumlah kebutuhannya, sedangkan untuk penyaluran pertamax dan solar mengalami kekurangan. Perbandingan prediksi kebutuhan BBM perbulan pada Tabel 10 dibandingkan dengan prediksi persedian optimal BBM perbulan pada Tabel 11 di tampilkan pada Tabel 13. Dari Tabel 13 diperoleh semua persediaan BBM mencukupi kebutuhan konsumen dan keuntungan perusahaan lebih besar dibandingkan dengan keuntungan perusahaan pada Tabel 12.

\subsection{Pembahasan}

Persedian BBM dilakukan untuk memenuhi kebutuhan masyarakat agar tidak terjadi kekurangan. Berdasarkan hasil penyelesaian diatas dengan menggunakan metode GP didapatkan persedian optimal premium bulan Februari sebesar 1.156 .000 liter dengan $\left(X_{1}\right)$ adalah 1 kali penyaluran premium bulan Februari dengan kebutuhan konsumen (Kendaraan) bulan Februari sebesar 1.057.108,30 liter, dengan deviasi $d_{1}^{+}=98.891,70$ liter, persedian optimal pertamax per bulan sebesar 352.000 liter dengan $\left(X_{2}\right)$ adalah 44 kali banyaknya penyaluran pertamax perbulan dengan kebutuhan konsumen (kendaraan) bulan Mei sebesar $349.317,70$ liter, dengan deviasi $d_{2}^{+}=2.682,30$ liter, persedian optimal solar bulan Februari sebesar 964.000 liter dengan $\left(X_{3}\right)$ adalah 2 kali penyaluran solar bulan Februari dengan kebutuhan konsumen (kendaraan) bulan Februari sebesar 726.798,80 liter, dengan deviasi $\mathrm{d}_{3}^{+}=237.201,20$ liter.

Berdasarkan hasil penyelesaian bahwa memaksimalkan keuntungan bulan Februari yang diperoleh telah dicapai sesuai dengan target keuntungan sebelumnya dimana target keuntungan bulan Februari sebesar Rp. 329.200.000 dan hasil perhitungan bulan Februari sebesar Rp. 494.400.000, sehingga nilai rupiah dimana target keuntungan bulan Februari yang ditetapkan melebihi target sebesar Rp. 165.200.000 yang diperoleh dari nilai $\mathrm{d}_{4}^{+}$. Kendaraan di Kota Poso mengalami peningkata. Rata-rata pertumbuhannya kendaraan perbulan adalah sepeda motor pribadi mengalami peningkatan sebesar 52 unit perbulan, mobil pribadi mengalami peningkatan sebesar 10 unit per bulan, angkutan niaga mengalami peningkatan sebesar 1 unit per bulan sedangkan angkutan umum mengalami penurunan sebesar 10 unit per bulan. Dengan meningkatnya jumlah kendaraan maka jumlah kebutuhan BBM pun mengalami meningkat setiap bulanya yaitu Premium sebesar 2.543,6 liter dan solar sebesar 1.363,6 liter. 
Dengan meningkatnya kebutuhan BBM di Kota Poso, maka kita dapat melakukan prediksi kebutuhan BBM perbulan dan persediaan optimal BBM perbulan dimana prediksi kebutuhan dan persedian optimal BBM perbulan ditunjukan pada tabel 10 dan tabel 11. Dengan persediaan optimal bulan Ferbruari digunakan sebagai patokan untuk menentukan prediksi kebutuhan dan persediaan optimal perbulan.

Bila dibandingkan prediksi kebutuhan BBM dengan penyaluran BBM perbulan pada tahun 2014 pada tabel 12, maka premium mengalami kelebihan kuota tetapi untuk pertamax dan solar mengalami kekurang kuota. Dan kelebihan kuota premium tidak cukup untuk memenuhi kekurangan pertamax. Sedangkan untuk perbandingan prediksi kebuthan BBM dengan prediksi persediaan optimal perbulan pada tabel 13, maka BBM di Kota Poso tidak akan mengalami kekurangan Kuota dan Perusahaan mendapatkan keuntungan lebih besar dari pada penyaluran BBM Tahun 2014.

\section{KESIMPULAN}

Berdasarkan hasil penelitian dan uraian-uraian pada bab-bab sebelumnya, maka dapat disimpulkan bahwa:

1. Persedian optimal BBM untuk bulan Maret - Desember 2014 harus meningkat secara periodik dengan tingkat pertambahan sebesar 2.543,60 liter perbulan untuk premium dan solar sebesar 1.363,63 liter perbulan. Persediaan optimal pada bulan-bulan tersebut mengacu pada persediaan optimal premium pada bulan Februari sebesar 1.156.000 liter, solar sebesar 352.000 liter dan pertamax sebesar 482.000 liter (lihat Tabel 13).

2. Keuntungan perusahan meningkat sebesar Rp. 165.200 .000 dimana target keuntungan perusahaan sebelumnya Rp.329.200.000 meningkat menjadi sebesar Rp. 494.400.000.

\section{DAFTAR PUSTAKA}

[1]. Aditya, N. 2013. Pendistribusian Bahan Bakar Minyka Non Subsidi di Wilayah Kota Pontianak Kalimantan Barat. Fakultas IImu Sosial dan Politik Universitas Tanjungpua. Pontianak.

[2]. Arif, M. 2012. Model Optimasi Persediaan Bahan Bakar Minyak (BBM) pada Pertamina UPMS VII Depot Donggala dengan Menggunakan Metode Goal Programming. Fakultas MIPA Universitas Tadulako. Palu.

[3]. BPS Indonesia. 2013. Perkembangan Jumlah Kendaraan Bermotor Menurut Jenis Tahun 1987-2013. www.bps.go.id. Diakses tanggal 10 Januari 2015. 
[4]. Firdaus, M.H. 2010. Model Goal Programming untuk Menentukan Persediaan Optimal Bahan Bakar Minyak (BBM) di PT. Pertamina Region / Medan. Fakultas MIPA Universitas Sumatera Utara. Medan.

[5]. Fiskal. 2014. Pengertian BBM Subsidi. www.fiskal.co.id. Diakses tanggal 20 november 2014.

[6]. Hartini. 2015. Penerapan Metode Goal Programming Untuk Memaksimalkan Persediaan dan Meminimumkan Biaya Pendistribusian beras di Perum Bulog divre Palu. Fakultas MIPA Universitas Tadulako. Palu.

[7]. Jayanti, D.Y. dkk. 2009. Analisis Penjualan Bahan Bakar Minyak Untuk Industri di PT. Pertamina (Persero) Cabang Bandung. Fakultas Teknik dan Ilmu Komputer Universitas Komputer Indonesia. Bandung.

[8]. Metrotvnews. 2014. Rancangan Undang-undang APBN BBM bersubsidi.. www.metrotvnews.com. Diakses tanggal 22 Januari 2015.

[9]. Taringan, R. E. S. 2010. Perencanaan Kapasitas Produksi Menggunakan Metode Linear Goal Programming di PT. Toba Surimi industri. Fakultas Pertanian Universitas Sumatra Utara. Medan.

[10]. Tempo. 2015. Kendaraan Bermotor di Indonesia Terbanyak di Asia. www.tempo.com., Diakses tanggal 22 Januari 2015. 